\title{
The Garbage Enzyme with Chinese Hoenylocust Fruits Showed Better Properties and Application than When Using the Garbage Enzyme Alone
}

\author{
Sitong Gu ${ }^{1,2}$, Dongying $\mathrm{Xu}^{1,2}$, Fuhui Zhou ${ }^{1,2}$, Chen Chen ${ }^{1,2}$, Chenghui Liu ${ }^{1,2}$, Mixia Tian ${ }^{1,2}$ and Aili Jiang ${ }^{1,2, *}$ \\ 1 Key Laboratory of Biotechnology and Bioresources Utilization, Ministry of Education, Dalian 116600, China; \\ gusitong0478@163.com (S.G.); 18840875773@163.com (D.X.); zhoufuhuihui@126.com (F.Z.); \\ chenchen@dlnu.edu.cn (C.C.); liuchenghui@dlnu.edu.cn (C.L.); tmx@dlnu.edu.cn (M.T.) \\ 2 College of Life Sciences, Dalian Minzu University, Dalian 116600, China \\ * Correspondence: jal@dlnu.edu.cn; Tel.: +86-411-87656203
}

Citation: Gu, S.; Xu, D.; Zhou, F. Chen, C.; Liu, C.; Tian, M.; Jiang, A. The Garbage Enzyme with Chinese Hoenylocust Fruits Showed Better Properties and Application than When Using the Garbage Enzyme Alone. Foods 2021, 10, 2656. https:// doi.org/10.3390/foods10112656

Academic Editor: Dong-Woo Lee

Received: 7 August 2021

Accepted: 18 October 2021

Published: 2 November 2021

Publisher's Note: MDPI stays neutral with regard to jurisdictional claims in published maps and institutional affiliations.

Copyright: (C) 2021 by the authors Licensee MDPI, Basel, Switzerland. This article is an open access article distributed under the terms and conditions of the Creative Commons Attribution (CC BY) license (https:// creativecommons.org/licenses/by/ $4.0 /)$

\begin{abstract}
Garbage enzyme (GE) is a vinegar or alcohol product derived from fermenting fresh kitchen waste, such as vegetable and fruit residues (peels, cuttings and bits), sugar (brown sugar, jaggery or molasses sugar) and water. Chinese honeylocust fruits (Gleditsia sinensis) have been used in China for at least 2000 years as a detergent. The aim of the study was to investigate the properties and application of Chinese honeylocust garbage enzyme (CHGE), which is produced when equal amounts of Chinese honeylocust fruits and fresh wastes are mixed. The results showed that CHGE had lesser microbial communities and lower surface tension than GE. CHGE also had higher viscosity, foam stability and emulsion stability than GE. Compared with GE, CHGE induced higher enzymatic amylase, cellulase, lipase and protease activities. CHGE had stronger detergency than GE and a $100 \times$ dilution of CHGE could significantly remove pesticide residues after a 30 min soaking treatment. The study showed that as a biological detergent, CHGE is safer and more environmentally friendly than GE and has remarkable washing and cleaning power. The preparation method of the detergent is simple: it can be prepared at home using fruit and vegetable waste, which is beneficial to the secondary utilization of waste and the reduction of pollution to the environment and damage to human health.
\end{abstract}

Keywords: Chinese honeylocust fruits; garbage enzyme; detergent; detoxification agent

\section{Introduction}

An enormous amount of fruit and vegetable waste is generated in the world due to high production and the lack of effective preservation measures. In addition, with the improvement of the quality of people's life, as well as the increasing demand for fresh, nutritious and convenient foods, a fresh-cut food industry has emerged and developed very quickly. Fresh-cut products are fruits or vegetables that have been trimmed and/or peeled, or cut into $100 \%$ edible products. However, the growing fresh-cut industry has also brought with it large amounts of fruit and vegetable peels and pits, and how to dispose of the fresh cut waste has become a hot topic. The traditional treatments, such as landfill and incineration result in groundwater pollution and the release of carbon dioxide, a greenhouse gas, causing serious environmental pollution and health risks to living organisms. Therefore, alternative environmentally-friendly treatments for fruit and vegetable wastes are urgently needed in order to make use of the wastes and increase the added value of fruit and vegetables as well as minimize the pollution problems created by them. Cleaning products are necessities in our life, and the use of chemical detergents affects human health and causes environmental pollution. Natural-derived products are becoming a new trend in the household products market. Currently, although there are a variety of washing products on the market, including plant extracts and enzyme detergents, 
they still cannot meet people's requirements for safety and low price, and are not conducive to the reuse of waste.

Garbage enzyme (GE) is produced by fermentation of waste fruits, vegetables or their peels, sugar (brown sugar or molasses sugar) and water using a method developed by Rosukon in 2006 [1]. It can be a viable method for turning food wastes into a useful resource for the production of higher-value-added products through fermentation processes due to its higher rate of degradation within a shorter period; additionally, the garbage enzyme production cost is cheaper, as it is produced from organic solid waste [2]. It was reported that GE could be used as fertilizer, plant growth hormones, pesticide, insecticide, wastewater treatment and antimicrobial agent, and the functions of GE may be different at different concentrations [3]. Till now, GE research has focused on improving water quality, as well as stabilizing industrial waste activated sludge [4-6]. However, to the best of our knowledge no literature to date has been devoted to the scientific study of GE's components, the effects of its usage and the mechanisms of its reactions with the aim of developing washing products.

Chinese honeylocust (Gleditsia sinensis Lam.) is a perennial arbour belonging to the Leguminosae family, which is widely distributed in most parts of the world, especially in China [7]. The most important components of Chinese honeylocust are triterpenoid saponins, triterpenes, flavonoids, alkaloids, phenolics and sterols [8]. Among them, triterpenoid saponins are the principal metabolites, with numerous pharmacological activities, and can be employed in the food and medicine fields [8]. In addition, the plant is a surfactant, and has the advantages of being powerful in activity, having decontaminating and foaming properties, is nontoxic to people and the environment, is easily biodegradable and is cheap, and thus is also used in a wide range of applications in the cosmetics, shampoo and washing industries $[9,10]$. With the development of the chemical industry, the detergent in Chinese honeylocust was extracted using chemical reactions. However, these chemical treatments waste energy and are not environmentally friendly [11,12].

The analysis of the above cited literature led us to conclude that the garbage enzyme has mainly been used for wastewater treatment, but no in-depth studies were reported on the usage of fruit and vegetable waste as garbage enzyme washing products. Furthermore, the detergent development and efficacy of GE combined with Chinese honeylocust have not been reported to date. Therefore, the purpose of the study was to find an environmentally friendly detergent by using CHGE, in which GE was used to release the active detergent substances from Chinese honeylocust fruits. The microbial communities and their structure in GE and CHGE were studied by high-throughput sequencing. The detergent characteristics were determined, the activities of washing-related enzymes were investigated, and the detoxification and decontamination abilities of CHGE and GE were measured to explore the possible application of CHGE in the washing industry. Meanwhile, the research can also provide reference for household fruit and vegetable waste utilization and homemade detergents.

\section{Materials and Methods}

\subsection{Preparation of $G E$ and $C H G E$}

To make the GE, fresh-cut apple scraps were pulverized using a pulverizer (JYL-G12, Jiuyang Co., Ltd., Jinan, China). One part of brown sugar, three parts of apples particles, and ten parts of water were thoroughly mixed and put in a well-sealed receptacle to ensure airtight conditions [1] (Figure 1). Similarly, to make the CHGE, one part of brown sugar, one and a half parts of fresh apple wastes, one and a half parts of ground Chinese honeylocust fruit powder and ten parts of water were mixed and then placed in sealed receptacles for anaerobic fermentation for three months at room temperature. The fermented materials were filtered three months later, and the liquid was diluted 0-, 10-, 50-, 100-, 200-, and 500fold for further experiments. The commercial detergent WhiteCat (Shanghai and Huangbai Cat Co., Ltd., Shanghai, China) was diluted 100-fold as a control for further analysis. 


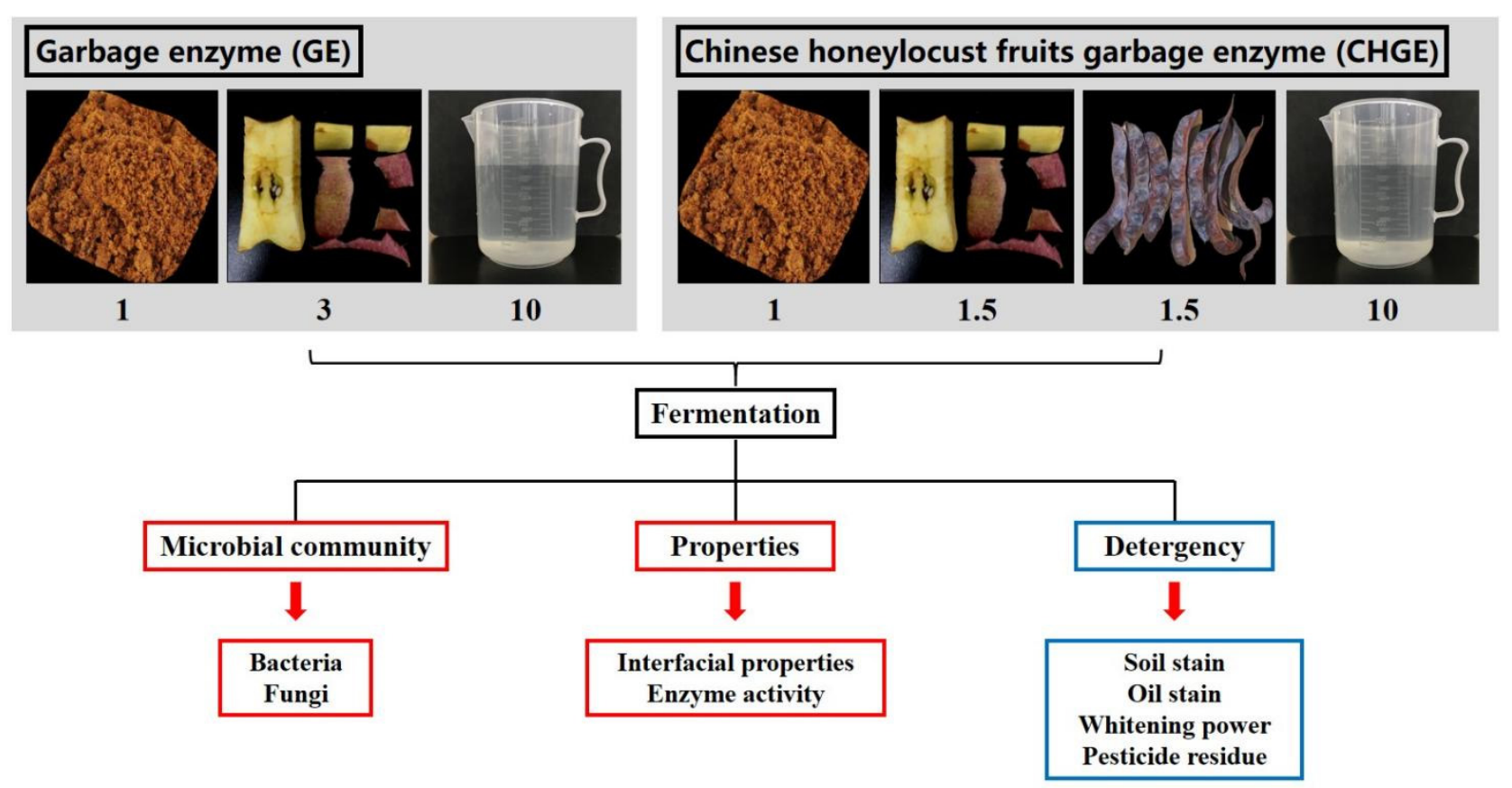

Figure 1. Schematic representation of the experiment workflow.

\subsection{High-Throughput Sequencing of the Microbial Communities}

High-throughput sequencing was used to identify the microbial communities in CHGE and GE. The DNA from GE and CHGE was extracted using the Fermentation Broth DNA Kit (MoBio Laboratories, Carlsbad, CA, USA) according to the manufacturer's instructions. A $0.8 \%$ agarose gel was used to check the purity and quality of the genomic DNA. Illumina Mi Seq sequencing was used to sequence the purified genomic DNA from GE and CHGE. For bacterial DNA, the primers 338F (ACTCCTACGGGAGGCAGCAG) and 806R (GGACTACHVGGGTWTCTAAT) [13] were used to amplify the V3-4 hypervariable region of bacterial $16 \mathrm{~S}$ rRNA. The PCR was carried out on a Mastercycler Gradient (Eppendorf, Hamburg, Germany) using the following parameters: initial denaturation at $95{ }^{\circ} \mathrm{C}$ for $5 \mathrm{~min}$, followed by 32 cycles of $95^{\circ} \mathrm{C}$ for $45 \mathrm{~s}, 55^{\circ} \mathrm{C}$ for $50 \mathrm{~s}$ and $72{ }^{\circ} \mathrm{C}$ for $45 \mathrm{~s}$, then followed by a final extension at $72{ }^{\circ} \mathrm{C}$ for $10 \mathrm{~min}$. The PCR products were purified using a QIAquick Gel Extraction Kit (QIAGEN, Hilden, Germany), quantified using Real Time PCR, and sequenced at Allwegene Company (Beijing, China). For the fungal genomic DNA, the ITS region was amplified using ultra PAGE purified primers (Invitrogen, Carlsbad, California, USA) ITS1F (5-CTTGGTCATTTAGAGGAAGTAA-3) and ITS2 (5-TGCGTTCTTCATCGATGC-3) [14]. The PCR was performed at an initial denaturation at $95^{\circ} \mathrm{C}$ for $2 \mathrm{~min}$, followed by 30 cycles of $95^{\circ} \mathrm{C}$ for $30 \mathrm{~s}, 55^{\circ} \mathrm{C}$ for $30 \mathrm{~s}, 72{ }^{\circ} \mathrm{C}$ for $30 \mathrm{~s}$ and a final extraction at $72{ }^{\circ} \mathrm{C}$ for $5 \mathrm{~min}$. Three independent PCR reactions were performed per sample for potentially heterogeneous amplification from the environmental templates. The PCR products were purified using the AXYGEN Gel Extraction Kit (QIAGEN) and quantified using qPCR.

Deep sequencing was performed on the Miseq platform at Allwegene Company. The image analysis, base calling and error estimation were analyzed using Illumina Analysis Pipeline Version 2.6. Richness estimators (Chao1) and diversity indices (Shannon) of each sample were calculated using the software Mothur (version 1.40.0, The University of Michigan, Ann Arbor, MI, USA). To compare the membership and structure of communities in different samples, heat maps were generated with the top 20 OTUs (operational taxonomic unit) using Mothur [15]. 


\subsection{Interfacial Properties of GE and CHGE}

The surface tension, viscosity, foam stability and solution stability were investigated to compare the characteristic interfacial properties of GE and CHGE. The surface tension of the diluted GE and CHGE was tested using a fully automatic surface tension meter equipped with a platinum pendant (BZY-1, Shanghai Hengping Instrument and Meter Factory, Shanghai, China). The viscosity of GE and CHGE was determined using a rotational viscometer (NDJ-79, Shanghai Changji Geological Instrument Co., Ltd., Shanghai, China). A foam test apparatus (2151 Roche foam tester, Beijing Jinzhiye, Beijing, China) was used to measure foam stability. The foam stability for each solution was recorded by the halflife, which is equivalent to the time required to reduce the initial foam volume by $50 \%$. Conductometric measurement was used to test the stability of GE and CHGE (DDS-307, Shanghai Precision Science Instrument Co., Ltd., Shanghai, China) by recording the voltage potential of the top and the bottom of the solutions [16]. All of the experiments mentioned above were performed at room temperature $\left(25^{\circ} \mathrm{C}\right)$.

\subsection{Biocatalytic Activity of GE and CHGE}

To compare the biocatalytic activity of GE and CHGE, the enzymatic activities of amylase, cellulase, lipase and protease were analyzed.

\subsubsection{Amylase Activity}

The activity of extracellular amylase was estimated by determining the amount of reducing sugars released from starch, using the 3,5-dinitrosalicylic acid (DNSA) method [17] with some modifications. Four $20 \mathrm{~mL}$ plug test tubes were filled with $1 \mathrm{~mL}$ of GE or CHGE; then $2 \mathrm{~mL}$ of DNSA reagent was added to two of these tubes, followed by incubation at $40{ }^{\circ} \mathrm{C}$ for $10 \mathrm{~min}$, and then $1 \mathrm{~mL}$ of $1 \%$ starch was added to the tubes, which were then incubated at $40{ }^{\circ} \mathrm{C}$ for $5 \mathrm{~min}$. Reaction was stopped by the addition of $2 \mathrm{~mL}$ DNSA chromogenic reagent, which was boiled for $5 \mathrm{~min}$, to the two remaining test tubes. A total of $16 \mathrm{~mL}$ of distilled water was added after the tubes were cooled. The absorbance at $540 \mathrm{~nm}$ was read with a spectrophotometer (Shimadzu, Kyoto, Japan) and used to determine the amount of reducing sugars. The maltose was used as a standard. One unit of enzymatic activity was defined as the amount of enzyme that produces 1 mol of reducing sugar as maltose per minute at $540 \mathrm{~nm}$. The amylase activity was calculated as follows:

$$
\text { Amylase activity }[\mathrm{mg} /(\mathrm{min} \cdot \mathrm{g})]=\frac{\mathrm{mg} \text { of maltose released } \times \text { Dilution factor }}{\text { Volume of solutions } \times \text { Enzymatic reaction time }}
$$

\subsubsection{Cellulase Activity}

The cellulase activity was determined by the standard of the Committee of Biotechnology of the International Union of Pure and Applied Chemistry (IUPAC) [18]. To test the cellulose activity of GE and CHGE, $10 \mathrm{~mL}$ of GE or CHGE were added to $100 \mathrm{~mL}$ of phosphate buffer solution (PBS) $(50 \mathrm{mM}, \mathrm{pH}=7.0)$. A total of $0.5 \mathrm{~mL}$ of the GE or CHGE solution was mixed with $2 \mathrm{~mL}$ of $1 \%(w / v)$ carboxymethyl cellulose (CMC) dissolved in PBS in $10 \mathrm{~mL}$ of colorimetric tubes and incubated at $37^{\circ} \mathrm{C}$ for $10 \mathrm{~min}$, followed by quickly adding $2 \mathrm{~mL}$ of DNSA, and the tubes were boiled for $10 \mathrm{~min}$ for color reaction. Once the reaction was complete, the tubes were cooled with running water and the reaction solution was diluted to $10 \mathrm{~mL}$. The absorbance at $540 \mathrm{~nm}$ was read at room temperature with a Shimadzu spectrophotometer. One unit of cellulase activity is a representation of the weight of glucose catalyzed by hydrolysis of $\mathrm{CMC}$ at $37^{\circ} \mathrm{C}$ per hour.

$$
\text { Cellulase acticity }(\mu \mathrm{g} / \mathrm{h} \cdot \mathrm{g})=\frac{\mathrm{mg} \text { of glucose released } \times \text { Dilution factor }}{\text { Volume of solutions } \times \text { Enzymatic reaction time }}
$$




\subsubsection{Lipase Activity}

The lipase activity was determined by using the following method [19]. A total of $2.50 \mathrm{~mL}$ of ultra-pure water, $1 \mathrm{~mL}$ of Tris $\mathrm{HCl}$ buffer and $3 \mathrm{~mL}$ of olive oil were added to conical flasks and $1 \mathrm{~mL}$ of GE or CHGE was added to the flasks. The GE or CHGE solutions were mixed, followed by a $15 \mathrm{~min}$ incubation at $37^{\circ} \mathrm{C}$, and then $3 \mathrm{~mL}$ of $95 \%$ ethanol solution and 3-4 drops of phenolphthalein indicator were added to the reaction mixtures. The final reactions were titrated with $\mathrm{NaOH}$ until a light pink color appeared. One unit of lipase activity was expressed as the amount of enzyme that releases $1 \mathrm{~mol}$ of fatty acids per minute.

Lipase activity $(\mu / \mathrm{g})=\frac{(\text { Volume of } \mathrm{NaOH} \text { used for test }- \text { Volume of } \mathrm{NaOH} \text { used for blank }) \times \text { Dilution factor }}{\text { Volume of solution }}$

\subsubsection{Protease Activity}

A total of $1 \mathrm{~mL}$ of GE or CHGE was added to $2.5 \mathrm{~mL} 1 \%(w / v)$ casein solution dissolved in $50 \mathrm{mM}$ PBS (pH 7.5). A total of $2.5 \mathrm{~mL} 0.4 \mathrm{M}$ trichloroacetic acid solution was added into the mixture after incubation at $40^{\circ} \mathrm{C}$ for $10 \mathrm{~min}$. Then, $1 \mathrm{~mL}$ of $3 \times$ diluted Folin reagent was added to the reaction. The absorbance values were recorded at $660 \mathrm{~nm}$ with a spectrophotometer (Shimadzu) after incubation at $40{ }^{\circ} \mathrm{C}$ for $20 \mathrm{~min}$. Protease activity was defined as the amount of enzyme that releases $1 \mu \mathrm{g}$ tyrosine per gram of plant per minute [20].

$$
\text { Protease activity }(\mu / g)=\frac{\mathrm{mg} \text { of tyrosine released } \times \text { Dilution factor }}{\text { Volume of solutions } \times \text { Enzymatic reaction time }}
$$

\subsection{Test of Detergency}

The detergency of GE and CHGE was tested by using an ultrasonic cleaner (KQ5200DB, Kunshan Ultrasonic Instrument Co., Ltd., Kunshan, China) for the decontamination of fabrics treated with tillage soil and cooking oil at room temperature. A total of $20 \mathrm{~mL}$ of different dilutions of GE and CHGE was used for washing of the fabrics. Clean water was used as the negative control and commercial detergent was used as the positive control. The stirring type was automatic mode: power supply: $220 \mathrm{~V} / 50 \mathrm{~Hz}$; rated washing input power: $345 \mathrm{~W}$; weight of washing: $4.6-5.5 \mathrm{~kg}$; energy efficiency rating: secondary; washing time: $20 \mathrm{~min}$; drying for $5 \mathrm{~min}$. Unwoven fabric was cut into sizes of $1 \mathrm{~m} \times 1 \mathrm{~m}$, and nine pieces were used for each test. After washing, the cleaning effects of GE and CHGE were assessed by determining the whiteness of each fabric with a Chroma Meter (CR-400, Konica Minolta Optics, Inc., Tokyo, Japan). The detergency was calculated using the following Equation (5) [16]:

$$
\text { Detergency }(\%)=\left[\frac{\mathrm{C}-\mathrm{B}}{\mathrm{A}-\mathrm{B}}\right] \times 100
$$

where $A$ is the whiteness of the white cloth, $B$ is the whiteness of the dirty cloth before washing, and $C$ is the whiteness of the dirty cloth after washing.

\subsection{Detoxification Ability of GE and CHGE}

Pak-choi treated with pesticides was used to test the detoxification ability of GE and CHGE. The pak-choi was sprayed with a $1000 \times$ dilution of dichlorvos and chlorpyrifos repeatedly and evenly, and then the treated pak-choi was put in a ventilated area for $12 \mathrm{~h}$. Amounts of $5 \mathrm{~g}$ of pak-choi treated with the pesticides were soaked in GE or CHGE for $20 \mathrm{~min}, 30 \mathrm{~min}$ and $40 \mathrm{~min}$. The pak-choi was taken out and put into a beaker containing $10 \mathrm{~mL}$ of PBS (pH 8.0); $2.5 \mathrm{~mL}$ of the supernatant was taken out after 2 min of shaking, while $2.5 \mathrm{~mL}$ of PBS treated solution was used as control.

A total of $0.1 \mathrm{~mL}$ of acetylcholinesterase was mixed with the supernatant for $10 \mathrm{~min}$, and then $0.1 \mathrm{~mL}$ of dithiodinitrobenzoic acid and sodium hydrogen carbonate (a chromogenic reagent) and $0.1 \mathrm{~mL}$ of thioacetylcholine were added into the reaction. The enzyme 
inhibition rate was measured at $410 \mathrm{~nm}$ and the removal rate was calculated using the following Equation (6) [21]:

$$
\text { Inhibition rate }(\%)=\frac{\Delta \mathrm{Ac}-\Delta \mathrm{As}}{\Delta \mathrm{Ac}} \times 100
$$

where $\Delta \mathrm{Ac}$ is the change value of the absorbance of the control solution after $3 \mathrm{~min}$, and $\Delta \mathrm{As}$ is the change value of the absorbance of the sample solution after $3 \mathrm{~min}$ :

$$
\text { Removal rate }(\%)=\frac{\mathrm{Rc}-\mathrm{Rt}}{\mathrm{Rc}} \times 100
$$

where Rc is the inhibition rate of enzymes in the untreated sample, and Rt is the inhibition rate of enzymes in the treated sample.

\subsection{Statistical Analysis}

SPSS version 17.0 (SPSS Inc., Chicago, IL, USA) was used for all statistical analyses. Differences between GE and CHGE were determined using a one-way ANOVA and the means were compared using LSD at $p<0.05$.

\section{Results}

\subsection{Analysis of the Diversity of the Microbial Community in GE and CHGE}

High-throughput sequencing of bacteria and fungi was performed to determine the microbial community of GE and CHGE. Good's coverage of all the samples ranged from 99.43 to $99.95 \%$, indicating that the sequencing was reliable when identifying the majority of diversity in the GE and CHGE samples. In terms of the quantity of operational taxonomic unit (OTU), GE had 456 OTUs for bacteria and 133 OTUs for fungi, indicating that GE had a richer diversity of bacterial and fungal communities than that of CHGE, which had 310 OTUs for bacteria and 84 OTUs for fungi (Table 1). The values of Shannon and Chao 1 revealed that GE had more bacterial and fungal diversity than that of CHGE, further indicating that bacteria and fungi in the GE are richer than that in CHGE.

Table 1. OTUs, Good's coverage, and Chaol's and Shannon's index for high-throughput sequencing of $16 \mathrm{~S}$ rRNA and $18 \mathrm{~S}$ rRNA sequencing of the bacteria and fungi in GE and CHGE.

\begin{tabular}{ccccc}
\hline Sample ID & OTU & Good's Coverage & Chaol & Shannon \\
\hline GE_Bacteria & 456 & $99.58 \%$ & 275.19 & 4.74 \\
CHGE_Bacteria & 310 & $99.49 \%$ & 258.41 & 1.95 \\
GE_Fungi & 133 & $99.83 \%$ & 242.89 & 4.17 \\
CHGE_Fungi & 84 & $99.95 \%$ & 46.84 & 0.25 \\
\hline
\end{tabular}

Figure 2A shows the top 20 bacterial genera that showed higher relative abundance in GE and CHGE. The dominant genera present in GE were Caproiciproducens, an unidentified species, Tyzzerella, Sporomusa, and Lachnoclostridium_5, while Lactobacillus had the highest abundance in CHGE. The difference in relative abundance of genera between GE and CHGE was significant.

The differences of fungal community at the genus level are shown in Figure 2B. There were seven dominant genera in GE with a relative abundance of $>0.1 \%$ : an unidentified species, Mortierella, Dactylonectria, Guehomyces, Fusarium, Penicillium, and Rhodotorula. Candida were the only dominant genera present in CHGE. This experiment showed that the Chinese honeylocust fruits could significantly reduce the bacteria and fungi community of GE. 

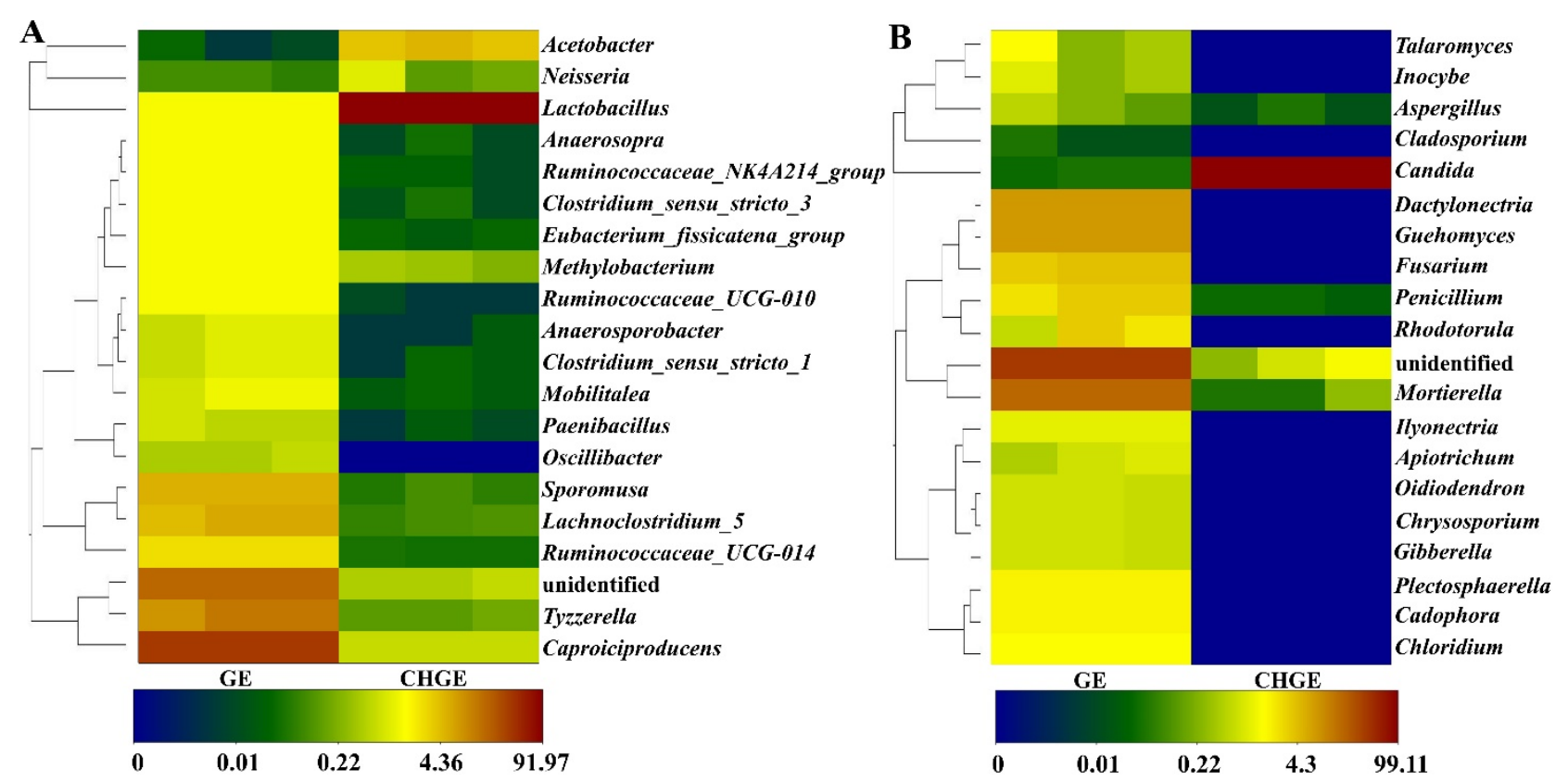

Figure 2. Heatmap clustering analysis of relative abundance of the top 20 communities for dominant bacterial genus (A) and fungal genus (B) in GE and CHGE.

\subsection{Interfacial Properties of GE and CHGE}

To characterize the interfacial property of GE and CHGE, the surface tension, viscosity, foam stability and solution stability of these detergents were investigated.

The $\mathrm{pH}$ value increased with the dilutions of GE and CHGE, but there was no difference between GE and CHGE at all dilutions (Table 2). The $\mathrm{pH}$ of the commercial detergent was 1.41 and 1.29 times that of GE and CHGE at 100 times dilution, respectively.

Table 2. Summary of interfacial properties of GE and CHGE at different dilutions at $25^{\circ} \mathrm{C}$.

\begin{tabular}{|c|c|c|c|c|c|c|c|c|}
\hline \multirow{2}{*}{ Sample } & \multirow{2}{*}{$\begin{array}{l}\text { Dilution } \\
\text { Times }\end{array}$} & \multirow{2}{*}{$\mathrm{pH}$} & \multirow{2}{*}{$\begin{array}{l}\text { Surface Tension } \\
(\mathrm{mN} / \mathrm{m})\end{array}$} & \multirow{2}{*}{$\begin{array}{l}\text { Viscosity } \\
(\mathrm{mPa} \cdot \mathrm{s})\end{array}$} & \multirow{2}{*}{ Foam Stability (s) } & \multicolumn{3}{|c|}{ Emulsion Stability $(\mu \mathrm{s} / \mathrm{cm})$} \\
\hline & & & & & & Top & Bottom & $\Delta \mathrm{E}$ \\
\hline \multirow{6}{*}{ GE } & 0 & 3.5 & 32.8 & 14.3 & 387 & 577.0 & 600.0 & 23.0 \\
\hline & 10 & 3.7 & 35.5 & 11.4 & 108 & 114.4 & 115.2 & 0.8 \\
\hline & 50 & 3.9 & 37.3 & 9.9 & 35 & 60.3 & 60.8 & 0.5 \\
\hline & 100 & 4.1 & 38.5 & 9.1 & 20 & 45.1 & 45.6 & 0.5 \\
\hline & 200 & 4.2 & 41.3 & 9.0 & $\begin{array}{l}\text { The foam disappears } \\
\text { after } 3-4 \mathrm{~s}\end{array}$ & 33.0 & 33.1 & 0.1 \\
\hline & 500 & 4.4 & 41.9 & 7.7 & $\begin{array}{l}\text { The foam disappears } \\
\text { after } 1-2 \mathrm{~s}\end{array}$ & 21.6 & 21.7 & 0.1 \\
\hline \multirow{6}{*}{ CHGE } & 0 & 3.7 & 28.6 & 14.1 & 400 & 576.0 & 590.0 & 14.0 \\
\hline & 10 & 3.8 & 30.8 & 11.9 & 123 & 114.9 & 115.4 & 0.5 \\
\hline & 50 & 4.0 & 31.4 & 10.3 & 38 & 60.1 & 60.6 & 0.5 \\
\hline & 100 & 4.5 & 32.6 & 9.7 & 21 & 45.3 & 45.6 & 0.3 \\
\hline & 200 & 4.8 & 38.2 & 9.2 & $\begin{array}{l}\text { The foam disappears } \\
\text { after } 3-4 \mathrm{~s}\end{array}$ & 32.7 & 32.9 & 0.2 \\
\hline & 500 & 5.1 & 40.7 & 7.9 & $\begin{array}{l}\text { The foam disappears } \\
\text { after } 1-2 \mathrm{~s}\end{array}$ & 21.3 & 21.6 & 0.3 \\
\hline $\begin{array}{l}\text { White } \\
\text { Cat }\end{array}$ & 100 & 5.8 & 23.8 & 16.2 & 2005 & 670.0 & 687.0 & 17.0 \\
\hline Water & & 6.8 & 44.2 & 1.0 & No foam appears & 1.2 & 1.3 & 0.1 \\
\hline
\end{tabular}


The surface tension increased with the dilution times for both GE and CHGE. The surface tension of CHGE was smaller than that of GE at all dilutions (Table 2). The water had highest surface tension $(44.2 \mathrm{nM} / \mathrm{m})$ and WhiteCat, the commercial detergent, had the lowest surface tension $(23.8 \mathrm{nM} / \mathrm{m})$ (Table 2$)$.

The viscosity of GE and CHGE decreased with the increase of the dilution times (Table 2). The commercial detergent WhiteCat had the highest viscosity of $16.2 \mathrm{mPa} \cdot \mathrm{s}$, while both the undiluted detergents had a value of $14.3 \mathrm{mPa} \cdot \mathrm{s}$ for GE and $14.1 \mathrm{mPa} \cdot \mathrm{s}$ for CHGE. No significant differences were found between GE and CHGE at all dilutions (Table 2).

The half-life of the foam (the time needed for half of the foam to disappear) was recorded to test the foam stability. Foam stability was consistent in both GE and CHGE, and the half-life was gradually shortened with the increase of the dilution times. Interestingly, the half-life of CHGE was longer than that of GE at all dilutions. The commercial detergent WhiteCat had the best foam stability, with a half-life of 2005 s, while the water, as expected, showed no foam (Table 2).

The emulsion stability of GE and CHGE was estimated by comparing the conductivity values of GE and CHGE. Except for undiluted GE and CHGE, the emulsion stability was considered to be stable for both GE and CHGE at all dilutions because there was no significant difference between the conductivity values for the top and bottom of these solutions (Table 2).

\subsection{The Activities of Washing-Related Enzymes in GE and CHGE}

The use of enzymes in detergent formulations is now common, with over half of all detergents presently available containing enzymes. The activity of four washing-related enzymes were compared in GE and CHGE. The results showed that the activities of amylase, cellulose and lipase of CHGE were significantly higher than that of GE $(p<0.05)$ (Figure 3A-C). However, no difference was found for protease activity between GE and CHGE (Figure 3D). It should be noted that the cellulase of CHGE was three times that of GE and the lipase activity of CHGE was 2.2 times that of GE (Figure 3B,C).

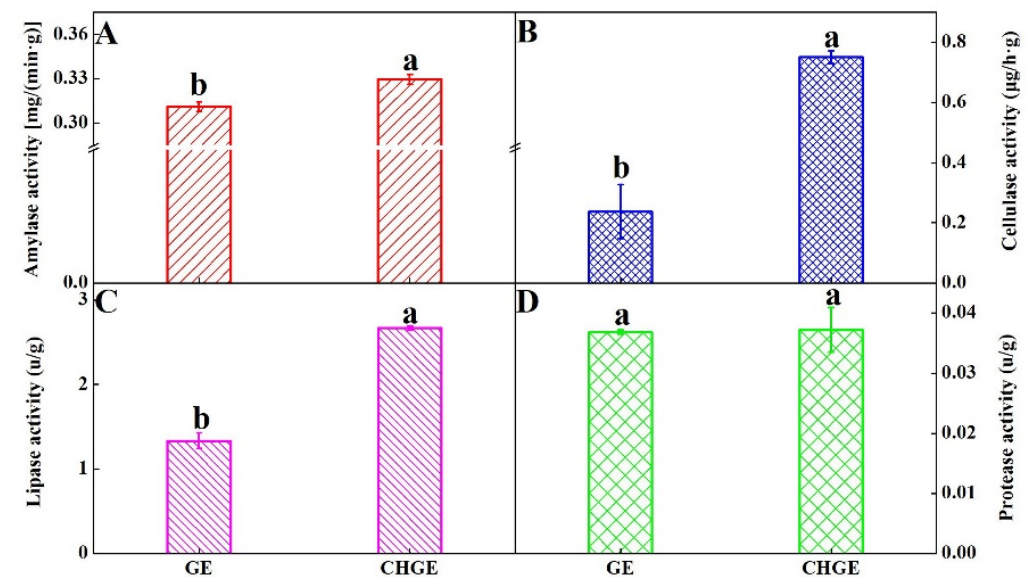

Figure 3. Activities of amylase (A), cellulase (B), lipase (C), and protease (D) of GE and CHGE. Data represent the mean $\pm \operatorname{SD}(n=3)$. Different letters indicate significant differences $(p<0.05)$ between GE and CHGE.

\subsection{Decontamination Ability of GE and CHGE}

Tillage soil and cooking oil were used to contaminate fabric samples and then GE and CHGE were used as detergents to wash them. With the increase of dilution times, the decontamination ability of the two garbage enzyme types on the soil stain both increased and reached the highest detergency at 100-fold dilution, and then decreased with the dilution times (Figure 4A). The detergency of CHGE at 0-200-fold dilutions was significantly higher than that of GE $(p<0.05)$ (Figure $4 \mathrm{~A})$. It is worth mentioning that CHGE at $0-100$ times 
dilutions showed better ability in removing of the soil stains than the commercial detergent WhiteCat, and its soil stains removal power was 1.44 and 1.31 times than that of GE and WhiteCat, respectively (Figure 4A).

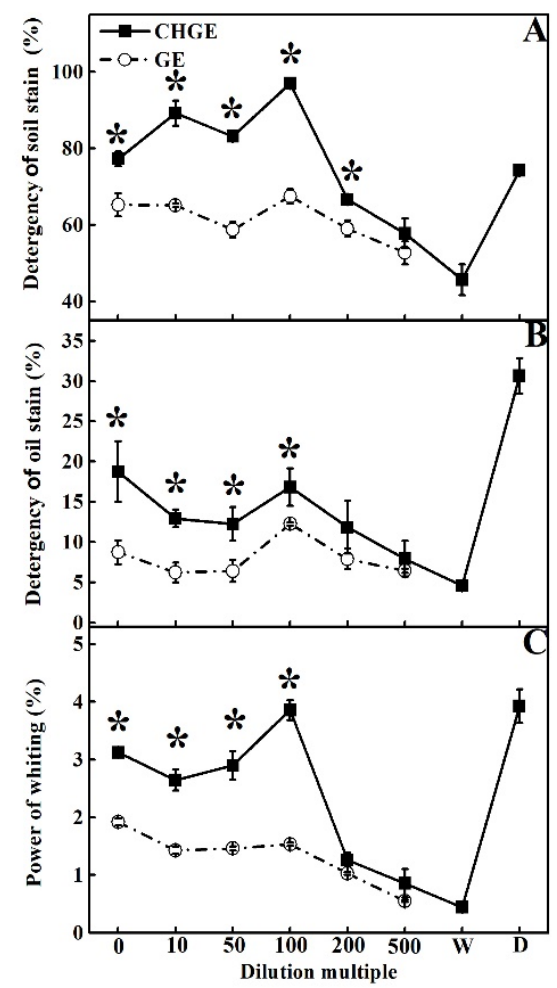

Figure 4. Effects of GE and CHGE on detergency of soil stains (A), oil stains (B), and whitening power (C). Data represent the mean $\pm \mathrm{SD}(n=3)$. Asterisks $\left(^{*}\right)$ indicate significant differences $(p<0.05)$ between GE and CHGE. D: commercial detergent (WhiteCat, Shanghai and Huangbai Cat Co., Ltd., Shanghai, China), W: deionized water.

For the detergency of the oil, the decontamination abilities of GE and CHGE had a similar tread to that for soil. The detergency of CHGE was higher at all dilutions and $0-100$ times dilutions was significantly higher than that of GE $(p<0.05)$ (Figure 4B). The commercial detergent WhiteCat had the best detergency for the oil stains (Figure 4B).

Both GE and CHGE showed whitening power on the fabrics (Figure 4C). The whitening power of CHGE was significantly higher than that of GE at 0-100-fold dilutions $(p<0.05)$. The best whitening value for CHGE was $3.86 \%$ at 100 -fold dilution, only slightly lower than that of the commercial detergent WhiteCat. However, the 500-fold dilution of GE had the weakest whitening power- $0.55 \%$, only 0.11 times higher than that of water (Figure 4C).

\subsection{Detoxification of GE and CHGE}

GE and CHGE were used as detoxification agents to wash the pak-choi treated with pesticides. Both CHGE and GE removed pesticides at all dilutions, and CHGE had higher removal rates than those of GE (Figure 5). Interestingly, both GE and CHGE had the best removal rate for dichlorvos residues and chlorpyrifos residues when diluted 100 times, even surpassing the ability of the commercial detergent (Figure 5). In terms of the soaking time, $30 \mathrm{~min}$ and $40 \mathrm{~min}$ soaking were better than $20 \mathrm{~min}$, but no significant difference between $30 \mathrm{~min}$ and $40 \mathrm{~min}$ treatments was found (Figure 5). After soaking for $40 \mathrm{~min}$, the removal rate of dichlorvos residue in CHGE was $21.97 \%$ and $64.20 \%$ higher than that in GE and the commercial detergent, respectively, and the removal rate of chlorpyrifos residues was $16.22 \%$ and $69.64 \%$ higher than that in GE and the commercial detergent, respectively. 


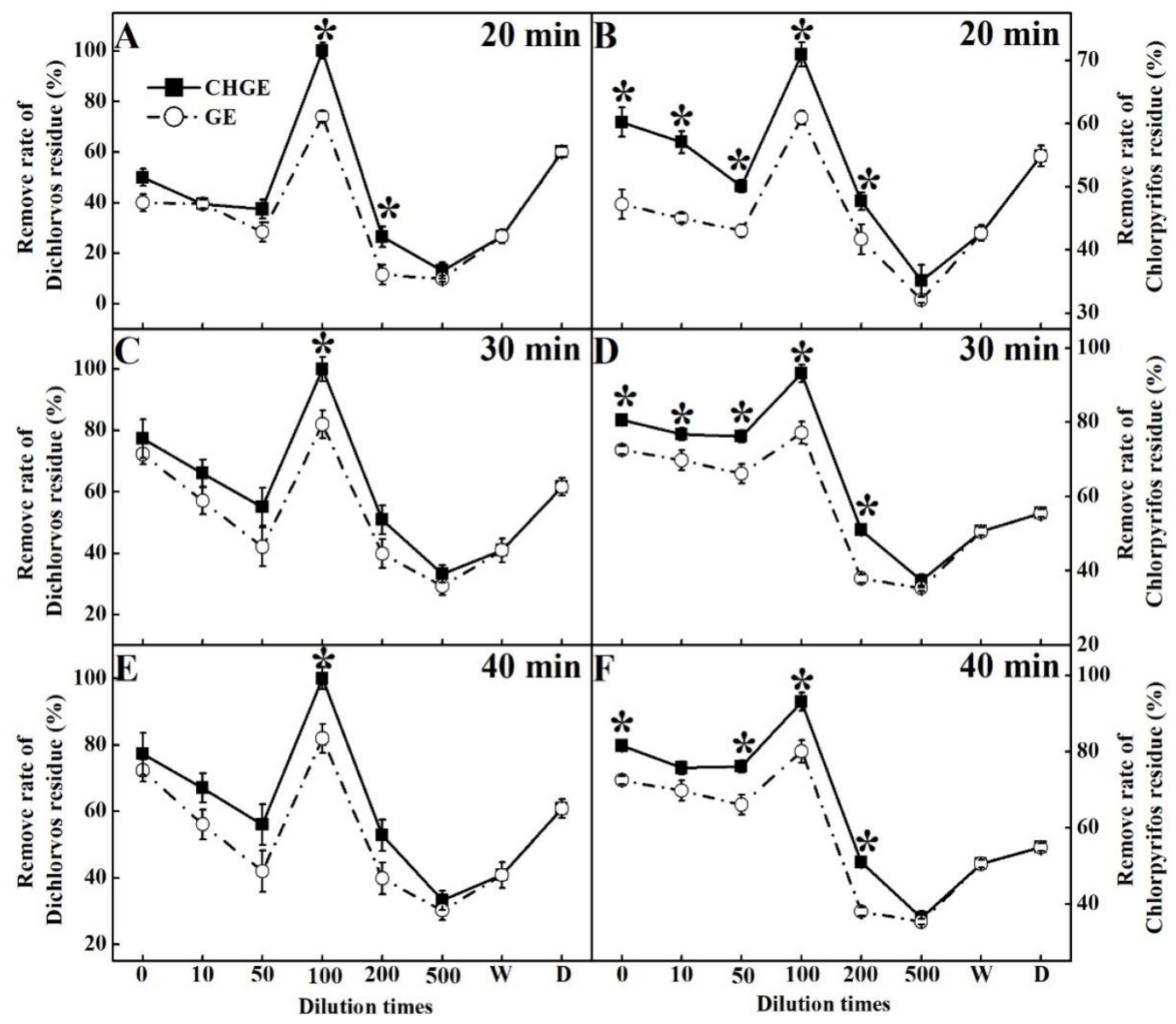

Figure 5. Effects of GE and CHGE on the removal rates of Dichlorvos and Chlorpyrifos residue after soaking the pak-choi for $20 \mathrm{~min}(\mathbf{A}, \mathbf{B}), 30 \mathrm{~min}(\mathbf{C}, \mathbf{D})$, and $40 \mathrm{~min}(\mathbf{E}, \mathbf{F})$. Data represent the mean $\pm \mathrm{SD}(n=3)$. Asterisks $\left(^{*}\right)$ indicate significant differences $(p<0.05)$ between GE and CHGE. D: commercial detergent (WhiteCat, Shanghai and Huangbai Cat Co., Ltd., Shanghai, China), W: deionized water.

\section{Discussion}

Restaurants, vegetable and fruit markets and food processing industries generate waste such as fruits, vegetables and their peels in huge quantities, which not only causes environmental pollution, but also threatens people's health. In the current study, fruit and vegetable waste and Chinese honeylocust were combined to produce a new detergent-CHGE - which can effectively treat the waste and improve the product value of the fruit and vegetable industry, and also ensure the safety of the detergent. The results indicated that CHGE contained significantly reduced microbial species. Most importantly, the microorganisms in CHGE are non-pathogenic, indicating the safety of CHGE as a detergent. The research also indicated that CHGE has better interfacial properties and higher enzymatic activity of the washing-related enzymes than that of GE, which led it to an efficient detergent. Additionally, the CHGE at 100-fold dilutions had higher detergency levels of soil stains and oil stains and higher whitening power than those of GE and the commercial detergent, and could also effectively remove pesticide residues; thus, it is a better detoxification agent than GE and the commercial detergent. The results of this study may contribute to the development of consumer products that are of natural origin, environmentally friendly and safe for human health.

The production process of GE is oxidation in the absence of air or through natural fermentation; the fermentation process and the acidic environment provide for the extraction of enzymes from the waste being fermented, and the acids and alcohols produced during fermentation make the GE an efficient anti-microbial agent [22]. It has been re- 
ported that Chinese honeylocust possesses anti-microbial, antibacterial and antifungal qualities [8]. Our results indicated that CHGE significantly reduced the species and relative abundance of bacterial genera and fungal genera compared with GE, which could be due to the addition of Chinese honeylocust, which enhanced the inhibition effect of the growth of microorganisms [23]. On the other hand, Chinese honeylocust is an alkaline substance [24] and can weaken the acidity of the GE; our research also suggested the $\mathrm{pH}$ value of CHGE was higher than that of GE, which could inhibit the growth of acidophilic bacteria and is safer than GE. Arun et al. [6] tested the antimicrobial activity of GE produced by fermentation and found that when the $\mathrm{pH}$ of the GE increased from 3.6 to 7 the activity of extracellular enzymes present in the GE solution increased, which in turn enhanced the antimicrobial activity and confirmed that the GE has a pathogen killing/inhibiting property. It is worth noting that Lactobacillus is a type of probiotic bacteria that can improve fermentation capacity; the relative abundance of Lactobacillus is higher in CHGE than in GE, while candida was the only dominant fungal genus presented in CHGE. These phenomena may be related to the addition of Chinese honeylocust, which is more suitable for the living environment of lactobacillus and candida. The results also indicated that CHGE is a safer detergent.

A foam is a complex dispersion of bubbles or gases in a liquid or solid matrix [25]. Foams are a common attribute of detergent products, and the surface tension and viscosity are related to form formation [26]. The aqueous phase bubbles consist of air bubbles in the water that are metastable and need to be stabilized by surface active molecules [27]. In many industrial and commercial applications, e.g., enhanced oil recovery, mineral flotation, food products, personal care products and detergents, the generation of foams as well as the foam stability are important [28]. Saponins can decontaminate and foam and have been extensively used in detergents, with high economic value [29]. However, in detergent applications, this does not mean the more the foam, the better the effect, because too much foam will increase unnecessary washing time and will waste water. Shendel et al. [30] also found the height of foam in distilled water produced by garbage enzyme to be lower than in commercial washing products, such as Nirma, Tide and Rin. On the other hand, the emulsion stability of GE and CHGE was determined by electrical conductivities on the top and bottom. In this study, foam stability was expressed by the half-life of the bubbles. The longer the half-life is, the more stable the foam is. The CHGE had longer half-lives than GE while little difference was found in conductivities when compared with GE, indicating that the CHGE is a better detergent than GE. Our results are consistent with the study of Do et al. [10], who indicated that the higher the concentration of saponin in the formulation, the higher the values of foam volume observed $10 \mathrm{~s}$ after its formation.

Enzymatic detergents are an emerging type of effective detergents, which now occupy a place of eminence among varied types of laundry detergents, and protease, lipase, amylase, and cellulase are the most commonly used enzymes in these formulations. Amylase is the most important enzyme in the washing industry and several studies have shown that amylase could degrade the residue of starchy foods [31]. Cellulase has a role in colorreviving agents in detergent [32]. Lipase adsorbs on the surface of the fabric to form a stable fabric-lipase compound, and hydrolyzes oil stains on the fabric during the washing [33]. Enzymatic detergents, even when they contain only very small amounts of enzymes, have significantly better washing effects than those who do not use enzymes. Enzyme products have been widely used as detergent builders in recent years because of their lower toxicity, non-corrosiveness, environmental friendliness, excellent biodegradability and increased improvement properties $[34,35]$. It has been reported that garbage enzymes produced from preconsumer organic waste contain multihydrolytic enzyme activity, which helps solubilize waste-activated sludge [36]. Amin et al. [2] reported that the maximum activity of lipase was found after $96 \mathrm{~h}$ of reaction in a fermentation medium with initial $\mathrm{pH} 4 \mathrm{using}$ agricultural waste as a raw material. The present study showed that CHGE had higher activities of amylase and cellulase than those of the GE group, which explains why CHGE had higher soil stain detergency and whitening power, and the detergency of soil stains 
was more effective than with commercial detergent, which agrees with the findings of Singh et al. [35] and Ladeira et al. [37]. CHGE also showed stronger detergency for oil stains, which can probably be attributed to its higher lipase activity. CHGE contains natural enzymes with higher activity and thus has stronger detergency ability.

Increasing pesticide use in recent years has led to public concern about the impacts of pesticide residues on human health and in the environment [38]. In the 21st century, the use of organic synthetic pesticides has increased about 40-fold, while organophosphorus pesticides account for 20-38\% of all pesticides all over the world [39], of which dichlorvos (2,2-dichlorovinyl dimethyl phosphate, DDVP) and chlorpyrifos (CHP, O,O-diethyl-O-[3,5,6-trichloro-2-pyridinyl], $\mathrm{C}_{9} \mathrm{H}_{11} \mathrm{C}_{13} \mathrm{NO}_{3} \mathrm{PS}$ ) are the most commonly used pesticides from the organophosphorus pesticides family. CHP is an irreversible inhibitor of cholinesterase, and is a most harmful pesticide to all animal species and humans [40]. As a chlorinated organophosphorus insecticide, DDVP is extremely toxic to humans. Acute exposure to DDVP can cause breathing problems, coma or even death [41]. It is very important to remove the residues of the pesticides in washing. Enzymatic bioremediation is potentially a rapid method of removing environmental pesticide residues [38]. Our study showed that both GE and CHGE could effectively remove CHP and DDVP sprayed on pak-choi, and 100-fold dilution of CHGE had the best effect in removing the pesticides, probably due to the lower surface tension of CHGE. Surface tension is the force between molecules, which decreases the surface area of a liquid [42]. It is believed that surface tension increases with a graduate increase in the hydrophilicity of a surfactant [43]. With the higher surface tension, CHGE has a stronger ability to remove pesticide residues at all dilutions. This could be due to the fact that the triterpenoid saponin contained in Chinese honeylocust fruits is a surfactant, which could reduce surface tension [44]. As is known, the main component of commercial detergents is a surfactant, which explains its surface tension was lower than other treatments even the detergent was diluted.

\section{Conclusions}

In conclusion, CHGE is a safe detergent because it has a relatively small microbial community and contains no pathogenic pathogens. CHGE at 100-fold dilution had the best washing ability based on the results of detergent characterization, enzyme activity and detergency. CHGE is also a potential detoxification detergent. Therefore, CHGE detergent is conducive to the secondary use of fruit and vegetable waste and the reduction of environmental pollution; additionally, it can be made at home with the characteristics of safety, low cost, convenience and pollution reduction, and can replace some commercially available washing products. In future work plan to continue to improve the cleaning efficacy of CHGE detergent, and prepare multi-functional and high-efficiency CHGE detergents to enhance commercial competitiveness.

Author Contributions: S.G.: Methodology, Software, Writing an original draft, Data curation, Validation. D.X.: Methodology, Software, Writing an original draft, Writing-review \& editing. F.Z.: Investigation, Validation, Software. C.C.: Conceptualization, Formal analysis. C.L.: Formal analysis. M.T.: Conceptualization. A.J.: Conceptualization, Supervision, Project administration, Writing-review \& editing. All authors have read and agreed to the published version of the manuscript.

Funding: This research was funded by the National Natural Science Foundation of China (31872908) and the Highlevel Innovation and Entrepreneurship Program in Dalian City (2021JJ12SN35).

Institutional Review Board Statement: Not applicable.

Informed Consent Statement: Not applicable.

Data Availability Statement: Not applicable.

Acknowledgments: The authors thank the College of Life Sciences (Dalian Minzu University) for providing support.

Conflicts of Interest: The authors declare no conflict of interest. 


\section{References}

1. Bhavani, P. How to Make and Use Garbage Enzyme. 2011. Available online: http:/ /www.ecowalkthetalk.com/ (accessed on 7 September 2018).

2. Arun, C.; Sivashanmugam, P. Study on optimization of process parameters for enhancing the multi-hydrolytic enzyme activity in garbage enzyme produced from preconsumer organic waste. Bioresour. Technol. 2017, 226, 200-210. [CrossRef] [PubMed]

3. Arun, C.; Sivashanmugam, P. Solubilization of waste activated sludge using a garbage enzyme produced from different preconsumer organic waste. RSC Adv. 2015, 5, 51421-51427. [CrossRef]

4. Tang, F.E.; Tong, C.W. A study of the garbage enzyme's effects in domestic wastewater. World Acad. Sci. Eng. Technol. 2013, 60, 1143-1148. [CrossRef]

5. Nazim, F.; Meera, V. Treatment of synthetic greywater using 5\% and $10 \%$ garbage enzyme solution. Bonfring Int. J. Ind. Eng. Manag. Sci. 2013, 3, 111-117. [CrossRef]

6. Arun, C.; Sivashanmugam, P. Investigation of biocatalytic potential of garbage enzyme and its influence on stabilization of industrial waste activated sludge. Process. Saf. Environ. Prot. 2015, 94, 471-478. [CrossRef]

7. Lee, J.-H.; Go, Y.; Lee, B.; Hwang, Y.-H.; Park, K.I.; Cho, W.-K.; Ma, J.Y. The fruits of Gleditsia sinensis Lam. inhibits adipogenesis through modulation of mitotic clonal expansion and STAT3 activation in 3T3-L1 cells. J. Ethnopharmacol. 2018, 222, 61-70. [CrossRef] [PubMed]

8. Shahrajabian, M.H.; Sun, W.; Khoshkharam, M.; Shen, H.; Cheng, Q. Study of Chinese honey locust (Gleditsia sinensis) and shallot (Allium ascalonicum L.) for integrate traditional Chinese medicine into other countries' medicine in order to improve public health. Labour. Prot. Probl. Ukr. 2020, 36, 8-14. [CrossRef]

9. Wang, Z.; Gu, M.; Li, G. Surface properties of Gleditsia saponin and synergisms of its binary system. J. Dispers. Sci. Technol. 2005, 26, 341-347. [CrossRef]

10. Do, D.N.; Dang, T.T.; Le, Q.T.; Lam, T.D.; Bach, L.G.; Nguyen, D.C.; Toan, T.Q. Extraction of saponin from gleditsia peel and applications on natural dishwashing liquid detergent. Mater. Today Proc. 2019, 18, 5219-5230. [CrossRef]

11. Wieck, S.; Olsson, O.; Kümmerer, K.; Klaschka, U. Fragrance allergens in household detergents. Regul. Toxicol. Pharmacol. 2018, 97, 163-169. [CrossRef]

12. Giagnorio, M.; Amelio, A.; Gruttner, H.; Tiraferri, A. Environmental impacts of detergents and benefits of their recovery in the laundering industry. J. Clean. Prod. 2017, 154, 593-601. [CrossRef]

13. Munyaka, P.M.; Eissa, N.; Bernstein, C.N.; Khafipour, E.; Ghia, J.-E. Antepartum antibiotic treatment increases offspring susceptibility to experimental colitis: A role of the gut microbiota. PLoS ONE 2015, 10, e0142536. [CrossRef]

14. Zhang, W.; Yuan, Y.; Yang, S.; Huang, J.; Huang, L. ITS2 secondary structure improves discrimination between medicinal “Mu Tong" species when using DNA barcoding. PLoS ONE 2015, 10, e0131185. [CrossRef] [PubMed]

15. Jami, E.; Israel, A.; Kotser, A.; Mizrahi, I. Exploring the bovine rumen bacterial community from birth to adulthood. ISME J. 2013, 7, 1069-1079. [CrossRef]

16. Lee, S.; Lee, J.; Yu, H.; Lim, J. Synthesis of environment friendly nonionic surfactants from sugar base and characterization of interfacial properties for detergent application. J. Ind. Eng. Chem. 2016, 38, 157-166. [CrossRef]

17. Bezerra, R.P.; Borba, F.K.S.L.; Moreira, K.; Lima-Filho, J.L.; Porto, A.L.F.; Chaves, A.C. Extraction of amylase from fermentation broth in poly (Ethylene glycol) salt aqueous two-phase system. Braz. Arch. Biol. Technol. 2006, 49, 547-555. [CrossRef]

18. Ghose, T.K. Measurement of cellulase activities. Pure Appl. Chem. 1987, 59, 257-268. [CrossRef]

19. Akova, A.; Ustun, G. Activity and adsorption of lipase from Nigella sativa seeds on Celite at different pH values. Biotechnol. Lett. 2000, 22, 355-359. [CrossRef]

20. Sun, Q.; Zhang, B.; Yan, Q.-J.; Jiang, Z.-Q. Comparative analysis on the distribution of protease activities among fruits and vegetable resources. Food Chem. 2016, 213, 708-713. [CrossRef] [PubMed]

21. Günther, A.; Bilitewski, U. Characterisation of inhibitors of acetylcholinesterase by an automated amperometric flow-injection system. Anal. Chim. Acta 1995, 300, 117-125. [CrossRef]

22. Sambaraju, S.; Lakshmi, V.S. Eco-friendly treatment of dairy wastewater using garbage enzyme. Mater. Today Proc. 2020, 33, 650-653. [CrossRef]

23. Mroczek, A.; Kapusta, I.; Stochmal, A.; Janiszowska, W. MS/MS and UPLC-MS profiling of triterpenoid saponins from leaves and roots of four red beet (Beta vulgaris L.) cultivars. Phytochem. Lett. 2019, 30, 333-337. [CrossRef]

24. Podolak, I.; Galanty, A.; Sobolewska, D. Saponins as cytotoxic agents: A review. Phytochem. Rev. 2010, 9, 425-474. [CrossRef]

25. Rio, E.; Drenckhan, W.; Salonen, A.; Langevin, D. Unusually stable liquid foams. Adv. Coll. Interface Sci. 2014, $205,74-86$. [CrossRef] [PubMed]

26. Sarker, D.K.; Wilde, P.J.; Clark, D.C. Competitive adsorption of 1- $\alpha$-lysophosphatidylcholine/ $\beta$-lactoglobulin mixtures at the interfaces of foams and foam lamellae. Coll. Surf. B Biointerfaces 1995, 3, 349-356. [CrossRef]

27. Manyala, D.L.; Rajput, G.; Pandya, N.; Varade, D. Enhanced foamability and foam stability of polyoxyethylene cholesteryl ether in occurrence of ionic surfactants. Coll. Surfaces A Physicochem. Eng. Asp. 2018, 551, 81-86. [CrossRef]

28. Zhang, L.; Tian, L.; Du, H.; Rouzière, S.; Wang, N.; Salonen, A. Foams stabilized by surfactant precipitates: Criteria for ultrastability. Langmuir 2017, 33, 7305-7311. [CrossRef]

29. Li, J.; Ye, C. Genome-wide analysis of microsatellite and sex-linked marker identification in Gleditsia sinensis. BMC Plant Biol. 2020, 20, 338. [CrossRef] 
30. Shende1, S.S.; Gawande, S.M.; Mandowara, P.Y. Study and identification of alternatives for detergents. Int. Res. J. Eng. Technol. 2021, 8, 809-812.

31. De Souza, P.M.; Magalhães, P.D.O. Application of microbial $\alpha$-amylase in industry-A review. Braz. J. Microbiol. 2010, 41, 850-861. [CrossRef]

32. Kuhad, R.C.; Gupta, R.; Singh, A. Microbial cellulases and their industrial applications. Enzym. Res. 2011, 2011, 280696. [CrossRef] [PubMed]

33. Sahay, S.; Chouhan, D. Study on the potential of cold-active lipases from psychrotrophic fungi for detergent formulation. J. Genet. Eng. Biotechnol. 2018, 16, 319-325. [CrossRef] [PubMed]

34. Reddy, M.R.; Reddy, K.S.; Chouhan, Y.R.; Bee, H.; Reddy, G. Effective feather degradation and keratinase production by Bacillus pumilus GRK for its application as bio-detergent additive. Bioresour. Technol. 2017, 243, 254-263. [CrossRef]

35. Singh, A.; Sharma, A.; Bansal, S.; Sharma, P. Comparative interaction study of amylase and surfactants for potential detergent formulation. J. Mol. Liq. 2018, 261, 397-401. [CrossRef]

36. Amin, M.; Bhatti, H.N.; Zuber, M.; Bhatti, I.A.; Asgher, M. Potential use of agricultural wastes for the production of lipase by aspergillus melleus under solid state fermentation. J. Anim. Plant Sci. 2014, 24, 1430-1437.

37. Ladeira, S.A.; Cruz, E.; Delatorre, A.B.; Barbosa, J.B.; Martins, M.L.L. Cellulase production by thermophilic Bacillus sp. SMIA-2 and its detergent compatibility. Electron. J. Biotechnol. 2015, 18, 110-115. [CrossRef]

38. Sutherland, T.; Horne, I.; Weir, K.; Coppin, C.; Williams, M.R.; Selleck, M.; Russell, R.; Oakeshott, J. Enzymatic bioremediation: From enzyme discovery to applications. Clin. Exp. Pharmacol. Physiol. 2004, 31, 817-821. [CrossRef]

39. Yaman, S.; Öztürk, N.; Çömelekoğlu, Ü.; Değirmenci, E. Determination of dichlorvos effect on uterine contractility using wavelet transform. IRBM 2016, 37, 264-270. [CrossRef]

40. Wang, Z.; Huang, J.; Chen, J.; Li, F. Effectiveness of dishwashing liquids in removing chlorothalonil and chlorpyrifos residues from cherry tomatoes. Chemosphere 2013, 92, 1022-1028. [CrossRef]

41. Cruz-Alcalde, A.; Sans, C.; Esplugas, S. Priority pesticides abatement by advanced water technologies: The case of acetamiprid removal by ozonation. Sci. Total Environ. 2017, 599-600, 1454-1461. [CrossRef]

42. Yılmaz, Z.; Aktemur, S.; Buzoglu, H.D.; Gümüsderelioglu, M. The effect of temperature and pH variations on the surface tension of EDTA solutions. J. Endod. 2011, 37, 825-827. [CrossRef] [PubMed]

43. Niraula, T.P.; Shah, S.K.; Chatterjee, S.K.; Bhattarai, A. Effect of methanol on the surface tension and viscosity of sodiumdodecyl sulfate (SDS) in aqueous medium at 298.15-323.15 K. Karbala Int. J. Mod. Sci. 2018, 4, 26-34. [CrossRef]

44. Cameron, J.A. The effect of a fluorocarbon surfactant on the surface tension of the endodontic irrigant, sodium hypochlorite. Aust. Dent. J. 1986, 31, 364-368. [CrossRef] [PubMed] 